КРАШЕНІНІН О.С., доктор технічних наук, професор кафедри експлуатації та ремонту рухомого складу

ШАПАТІНА О.О., кандидат технічних наук, старший викладач кафедри управління вантажною і комерційною роботою

(Український державний університет залізничного транспорту)

\title{
Визначення ефективності перевезень різними транспортними засобами
}

У статті розглянуто питання визначення ефективності перевезень різними транспортними засобами, які розглядаються як системи довготривалої дії. Відповідно до изього зазначено необхідність у рамках взаємодії різних транспортних засобів у процесі надання транспортних послуг комплексно враховувати спосіб виконання завдання та етапи його виконання.

Запропоновано як критерій ефективності перевезень використовувати критерій суми значень множини ймовірностей на показник ефективності.

Формалізовано процес визначення ефективності перевезень иляхом комбінування способів перевезень на кожному етапі виконання транспортних задач.

Ключові слова: багатофункиіональна система, показник технічної ефективності, імовірність безвідмовної роботи.

\begin{abstract}
Постановка проблеми
Залізничний транспорт України $є$ провідною галуззю в дорожньо-транспортному комплексі країни, що забезпечує майже $82 \%$ вантажних і $36 \%$ пасажирських перевезень, здійснюваних усіма видами транспорту [1]. Транспортні засоби використовуються для виконання завдань 3 переміщення вантажів або пасажирів між різними пунктами призначення. Для масового перевезення вантажів і пасажирів на великій відстані застосовується залізничний транспорт. Автомобільний транспорт забезпечує оперативну доставку вантажів і пасажирів у значно меншому одноразовому обсязі. Переваги інтермодального транспорту визначаються його мобільністю, дальністю транспортування.
\end{abstract}

Поєднання переваг усіх видів транспорту в єдиному процесі управління рухом дає змогу досягти високої ефективності завдяки вибору маршруту на основі маневрування типом транспортного засобу, його швидкості і вантажопідйомності.

Оскільки транспортні засоби належать до технічних систем довготривалого використання, постають завдання забезпечення високої ефективності їх функціонування, тобто кількісної оцінки виконання транспортними засобами своїх функцій.

В умовах конкуренції на ринку транспортних послуг вирішення цього завдання має актуальний характер.

() О. С. Крашенінін, О. О. Шапатіна, 2021

\section{Аналіз останніх досліджень і публікацій}

Підвищення ефективності транспортних перевезень залежить від оптимізації витрат на їх експлуатацію за життєвий цикл [2-4].

У нашій країні традиційно основна увага приділялася економії витрат на експлуатацію, технічне обслуговування та ремонт за рахунок оптимізації системи ремонту локомотивів для забезпечення i підтримки їх надійності $[5,6]$.

Теоретичні аспекти підвищення надійності відображено в роботах [7-9]. Окремі дослідження присвячені питанням енергозбереження при експлуатації тягового рухомого складу як за рахунок вибору оптимального режиму руху локомотива, так i коректуванням режимів управління локомотивом на основі дослідження даних [10-12].

Проводяться дослідження, що направлені на теоретичне і практичне обгрунтування ефективності подовження терміну експлуатації локомотивів завдяки їх модернізації та коректуванню стратегії ТО, ПР у післянормативний термін експлуатації $[13,14]$.

В умовах посилення конкуренції на ринку транспортних послуг актуальним питанням постає комплексне рішення визначення ефективності перевезень різними видами транспорту.

\section{Визначення мети і завдання дослідження \\ Метою дослідження $є$ визначення чинників, що впливають на ефективність перевезень при використанні різних транспортних засобів, і визначення цієї ефективності.}


Відповідно до цього поставлено такі завдання:

- запропонувати критерій оцінки ефективності перевезень;

- формалізувати процес визначення ефективності перевезень.

\begin{tabular}{cccc}
\hline Викладення основного матеріалу дослідження & \\
\hline Транспортні & системи & належать & до
\end{tabular} багатофункціональних систем, оскільки можуть виконувати завдання $з$ перевезень різними способами. Відповідно до цього ці способи перевезень можуть характеризуватися різними показниками ефективності. Однак зрозуміло, що при будь-якому стані системи слід обирати той спосіб перевезень, який для даного стану системи є оптимальним.

Транспортна система містить комплекс технічних засобів, які забезпечують транспортні операції (локомотиви, автомобілі, інтермодальний транспорт), управління і контролю рухом (системи сигналізації і зв'язку, служби диспетчерського управління транспортним парком, диспетчерського управління рухом, обчислювального центру і т. д.) i загалом складаються з багатьох конкретних для даної системи елементів.

Отже, задача 3 перевезення різноманітної номенклатури і обсягу продукції може виконуватись різними способами. Будемо вважати, що при перевезенні $j$-м способом умовний показник технічної ефективності системи дорівнює $F_{j}$. Нехай для визначеності $F_{1}>F_{2}>\ldots>F_{n}$.

Транспортну систему залежно від типу транспорту, обсягу i номенклатури продукції, що перевозиться, можна розділити на $n$ підсистем $Q_{1}, Q_{2}, \ldots, Q_{n}$ за умови, що в кожну таку підсистему входять складові, які забезпечують перевезення $j$-м способом.

Можливі такі варіанти оцінки ефективності функціонування транспортних систем:

- кожний елемент системи може входити в склад тільки однієї підсистеми;

- підсистеми можуть виконувати задачі 3 перевезень за умови працездатності як всіх елементів системи, так i лише частини, тобто $Q_{1} \supset Q_{2} \supset \ldots \supset Q_{n}$.

Відповідно до другого варіанта транспортна система буде підтримуватись $j$-м способом за умови, коли всі елементи підсистеми $Q_{j}$ працездатні, а в підсистемі $Q_{j-1}^{*} \epsilon$ хоча б один елемент, що відмовив $\left(Q_{j-1}^{*}\right.$ - множина елементів системи, які належать підсистемі $Q_{j-1}$ і одночасно не належать підсистемі $\left.Q_{j}\right)$.

Ефективність функціонування транспортної системи можна визначити таким чином:

$E=\sum_{i=1}^{n} F_{j}\left(P_{j}-P_{j-1}\right)$,

де відповідно $P_{j}, P_{j-1}$ - імовірності безвідмовної роботи $j$-ї та $j$-1 транспортної підсистеми.

Відповідно до цього розглянемо процедуру оцінки ефективності системи управління транспортного процесу (рис. 1).

Процес управління транспортною системою включає контроль руху, вибір транспортного засобу за допомогою служби диспетчерського управління транспортним парком, служби диспетчерського управління рухом та обчислювального центру.

Можливі комбінації способів виконання кожного окремого етапу, що забезпечуються транспортною системою процесу перевезень, і відповідні цим комбінаціям показники технічної ефективності зведені до табл. 1.

Зазначимо, що для виконання транспортного процесу будь-яким способом необхідно, щоб диспетчерська служба, що забезпечує управління рухом, завжди була працездатною.

Прийняті значення імовірності безвідмовної роботи елементів транспортної системи для деякого моменту часу подано в табл. 1. 


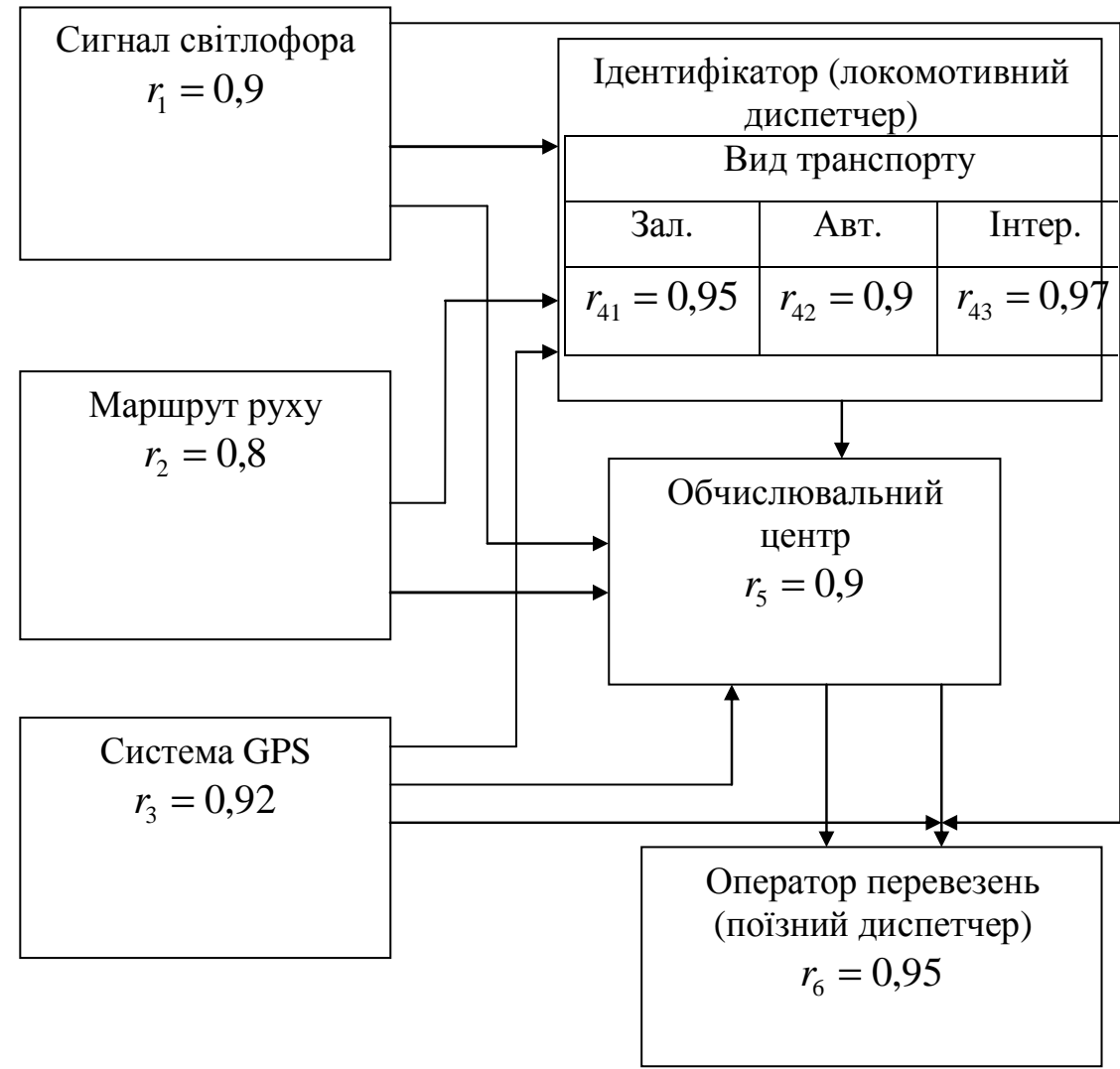

Рис. 1. Структурна схема системи транспортних перевезень

Показники технічної ефективності при різних системах обслуговування

\begin{tabular}{|c|c|c|c|c|}
\hline \multirow[b]{2}{*}{$\begin{array}{c}\text { Спосіб } \\
\text { виконання }\end{array}$} & \multicolumn{3}{|c|}{ Етапи } & \multirow[b]{2}{*}{$\begin{array}{c}\text { Показник } \\
\text { технічної } \\
\text { ефективності }\end{array}$} \\
\hline & $\begin{array}{c}\text { Вибір } \\
\text { транспортного } \\
\text { супроводження }\end{array}$ & $\begin{array}{c}\text { Визначення місця } \\
\text { знаходження }\end{array}$ & $\begin{array}{l}\text { Супровід виконання } \\
\text { задачі з перевезення }\end{array}$ & \\
\hline 1 & GPS & Ідентифікатор & Система GPS & 1,0 \\
\hline 2 & Маршрут руху & Ідентифікатор & Система GPS & 0,7 \\
\hline 3 & Маршрут руху & Ідентифікатор & $\begin{array}{c}\text { Сигнали світлофора, } \\
\text { обчислювальний } \\
\text { центр }\end{array}$ & 0,4 \\
\hline 4 & Сигнали світлофора & Сигнали світлофора & $\begin{array}{c}\text { Сигнали світлофора, } \\
\text { обчислювальний } \\
\text { центр }\end{array}$ & 0,2 \\
\hline 5 & Сигнали світлофора & Сигнали світлофора & $\begin{array}{c}\text { Сигнали світлофора, } \\
\text { обчислювальний } \\
\text { центр } \\
\end{array}$ & 0,1 \\
\hline
\end{tabular}


Оцінимо спочатку повну імовірність виконання транспортною системою задачі 3 перевезення деякої продукції.

Виконання задачі з перевезення першим способом оцінюється за формулою

$h_{1}=r_{1} \cdot r_{2} \cdot r_{3} \cdot r_{4} \cdot r_{5} \cdot r_{6}$

а) залізничним транспортом:

$h_{1}=r_{1} \cdot r_{2} \cdot r_{3} \cdot r_{41} \cdot r_{5} \cdot r_{6}$,

$h_{1}=0,9 \cdot 0,8 \cdot 0,92 \cdot 0,95 \cdot 0,9 \cdot 0,95=0,53 ;$

б) автомобільним транспортом:

$h_{1}=r_{1} \cdot r_{2} \cdot r_{3} \cdot r_{42} \cdot r_{5} \cdot r_{6}$,

$h_{1}=0,9 \cdot 0,8 \cdot 0,92 \cdot 0,9 \cdot 0,9 \cdot 0,95=0,5 ;$

в) інтермодальним транспортом:

$h_{1}=r_{1} \cdot r_{2} \cdot r_{3} \cdot r_{43} \cdot r_{5} \cdot r_{6}$

$h_{1}=0,9 \cdot 0,8 \cdot 0,92 \cdot 0,97 \cdot 0,9 \cdot 0,95=0,54$.

Виконання задачі другим способом може бути проведене тільки тоді, коли не визначено маршрут руху, тобто з імовірністю

$h_{2}=g_{1} \cdot r_{3} \cdot r_{4} \cdot r_{5} \cdot r_{6}$,

а) залізничним транспортом:

$h_{2}=g_{1} \cdot r_{3} \cdot r_{41} \cdot r_{5} \cdot r_{6}$

$h_{2}=(1-0,9) \cdot 0,92 \cdot 0,95 \cdot 0,9 \cdot 0,95=0,074$;

б) автомобільним транспортом:

$h_{2}=g_{1} \cdot r_{3} \cdot r_{42} \cdot r_{5} \cdot r_{6}$

$h_{2}=(1-0,9) \cdot 0,92 \cdot 0,9 \cdot 0,9 \cdot 0,95=0,071$

в) інтермодальним транспортом:

$h_{2}=g_{1} \cdot r_{3} \cdot r_{43} \cdot r_{5} \cdot r_{6}$,

$h_{2}=(1-0,9) \cdot 0,92 \cdot 0,97 \cdot 0,9 \cdot 0,95=0,076$.
Виконання задачі третім способом проводиться тільки тоді, коли виникла відмова системи GPS, тобто 3 імовірністю

$h_{3}=r_{1} \cdot g_{3} \cdot r_{4} \cdot r_{5} \cdot r_{6}$

a) залізничним транспортом:

$h_{3}=r_{1} \cdot g_{3} \cdot r_{41} \cdot r_{5} \cdot r_{6}$

$h_{3}=0,9 \cdot(1-0,92) \cdot 0,95 \cdot 0,9 \cdot 0,95=0,058 ;$

б) автомобільним транспортом:

$h_{3}=r_{1} \cdot g_{3} \cdot r_{42} \cdot r_{5} \cdot r_{6}$

$h_{3}=0,9 \cdot(1-0,92) \cdot 0,9 \cdot 0,9 \cdot 0,95=0,055$;

в) інтермодальним транспортом:

$h_{3}=r_{1} \cdot g_{3} \cdot r_{43} \cdot r_{5} \cdot r_{6}$

$h_{3}=0,9 \cdot(1-0,92) \cdot 0,97 \cdot 0,9 \cdot 0,95=0,059$.

Виконання задачі четвертим способом буде проводитися в тому випадку, коли виникла відмова:

- служби диспетчерського управління парком;

- служби диспетчерського управління парком i системи маршруту руху;

- служби диспетчерського управління парком i системи GPS;

- системи GPS і маршруту руху.

При цьому система сигналізації світлофорів i обчислювального центру функціонують справно. Імовірність цієї ситуації дорівнює

$h_{4}=r_{2} \cdot r_{5} \cdot r_{6} \cdot\left(g_{4} \cdot r_{1} \cdot r_{2}+g_{4} \cdot g_{1} \cdot r_{3}+g_{4} \cdot g_{1} \cdot g_{3}+r_{4} \cdot g_{1} \cdot g_{2}\right)$

а) залізничним транспортом:

$h_{4}=r_{2} \cdot r_{5} \cdot r_{6} \cdot\left(g_{41} \cdot r_{1} \cdot r_{2}+g_{41} \cdot g_{1} \cdot r_{3}+g_{41} \cdot g_{1} \cdot g_{3}+r_{41} \cdot g_{1} \cdot g_{2}\right)$,

$h_{4}=0,8 \cdot 0,9 \cdot 0,95 \cdot(0.05 \cdot 0,9 \cdot 0,8+0.05 \cdot(1-0,9) \cdot 0,92+$

$+0.05 \cdot(1-0,9) \cdot(1-0,92)+0,95 \cdot(1-0,9) \cdot(1-0.8))=0,041$;

б) автомобільним транспортом:

$h_{4}=r_{2} \cdot r_{5} \cdot r_{6} \cdot\left(g_{42} \cdot r_{1} \cdot r_{2}+g_{42} \cdot g_{1} \cdot r_{3}+g_{42} \cdot g_{1} \cdot g_{3}+r_{42} \cdot g_{1} \cdot g_{2}\right)$, 
$h_{4}=0,8 \cdot 0,9 \cdot 0,95 \cdot(0.1 \cdot 0,9 \cdot 0,8+0.1 \cdot(1-0,9) \cdot 0,92+$

$+0.1 \cdot(1-0,9) \cdot(1-0,92)+0,9 \cdot(1-0,9) \cdot(1-0.8)=0,068$;

в) інтермодальним транспортом:

$h_{4}=r_{2} \cdot r_{5} \cdot r_{6} \cdot\left(g_{43} \cdot r_{1} \cdot r_{2}+g_{43} \cdot g_{1} \cdot r_{3}+g_{43} \cdot g_{1} \cdot g_{3}+r_{43} \cdot g_{1} \cdot g_{2}\right)$

$h_{4}=0,8 \cdot 0,9 \cdot 0,95 \cdot(0.03 \cdot 0,9 \cdot 0,8+0.03 \cdot(1-0,9) \cdot 0,92+$

$+0.03 \cdot(1-0,9) \cdot(1-0,92)+0,97 \cdot(1-0,9) \cdot(1-0.8)=0,03$.

Виконання задачі п'ятим способом проводиться тільки у випадку, коли додатково ще відмовив обчислювальний центр, тобто з імовірністю

$h_{5}=r_{2} \cdot g_{5} \cdot r_{6} \cdot\left(g_{4}+g_{1} \cdot g_{3} \cdot r_{4}\right)$,

а) залізничним транспортом:

$h_{5}=r_{2} \cdot g_{5} \cdot r_{6} \cdot\left(g_{41}+g_{1} \cdot g_{3} \cdot r_{41}\right)$,

$h_{5}=0,8 \cdot(1-0.9) \cdot 0,95 \cdot(0.05+(1-0,9) \cdot(1-0,92) \cdot 0,95)=0,004$

б) автомобільним транспортом:

$h_{5}=r_{2} \cdot g_{5} \cdot r_{6} \cdot\left(g_{42}+g_{1} \cdot g_{3} \cdot r_{42}\right)$

$h_{5}=0,8 \cdot(1-0.9) \cdot 0,95 \cdot(0.1+(1-0,9) \cdot(1-0,92) \cdot 0,9)=0,0081$;

в) інтермодальним транспортом:

$h_{5}=r_{2} \cdot g_{5} \cdot r_{6} \cdot\left(g_{43}+g_{1} \cdot g_{3} \cdot r_{43}\right)$

$h_{5}=0,8 \cdot(1-0.9) \cdot 0,95 \cdot(0.03+(1-0,9) \cdot(1-0,92) \cdot 0,97)=0,002 !$

Тоді ефективність функціонування транспортної системи визначимо таким чином:

а) залізничним транспортом:

$E_{1}=0,53 \cdot 1+0,074 \cdot 0,7+0,058 \cdot 0,4+0,041 \cdot 0,2+0,0044 \cdot 0,1=$ $=0,53+0,0518+0,0232+0,0082+0,00044=0,6136$

б) автомобільним транспортом:

$E_{2}=0,5 \cdot 1+0,071 \cdot 0,7+0,055 \cdot 0,4+0,068 \cdot 0,2+0,0081 \cdot 0,1=$ $=0,5+0,0497+0,022+0,0136+0,00081=0,586$

в) інтермодальним транспортом:

$E_{3}=0,54 \cdot 1+0,076 \cdot 0,7+0,059 \cdot 0,4+0,03 \cdot 0,2+0,0029 \cdot 0,1=$ $=0,54+0,0532+0,0236+0,006+0,00029=0,623$
Наведена процедура визначення ефективності роботи транспортних систем може бути покладена в основу створення єдиного критерію оцінки комплексної взаємодії різних видів транспорту при перевезенні вантажів.

\section{Висновки 3 дослідження і перспективи подальшого розвитку у даному напрямі}

1. Визначено, що забезпечення ефективності роботи транспортних систем доцільно оцінювати на основі приведеного критерію ефективності 3 урахуванням комплексу станів при виконанні завдань i етапів їх виконання.

2. На основі критерію ефективності формалізовано процедуру вибору оптимального варіанта транспортного забезпечення шляхом комбінування способів перевезень на кожному етапі виконання транспортних завдань.

3. Згідно з поданими розрахунками доведено, що запровадження інтермодальних перевезень має найбільшу ефективність порівняно 3 іншими видами вантажних перевезень.

\section{Список використаних джерел}

1. Інформація про Українські залізниці. URL : https://mtu.gov.ua/content/informaciya-pro-ukrainskizaliznici.html.

2. Тартаковский Э. Д., Грищенко С. Г., Калабухин Ю. Е., Фалендыш А. П. Методы оценки жизненного цикла тягового подвижного состава железных дорог : монография. Луганск : Ноулидж, 2011.173 c.

3. Panchenko S., Lavrukhin O., Shapatina O. Creating a qualimetric criterion for the generalized level of vehicle. Eastern-European journal of enterprise technologies. 2017. Vol. 1, № 3(85). P. 39-45. DOI: 10.15587/1729-4061.2017.92203.

4. Yun, W.Y. \& Han, Y.J. \& Park, G. Optimal preventive maintenance interval and spare parts number in a rolling stock system. In: 2012 International Conference on Quality. Reliability, Risk. Maintenance, and Safety Engineering (ICQR2MSE). Chengdu, 2012.

5. Василевський О. М., Ігнатенко О. Г. Нормування показників надійності технічних засобів: навч. посіб. Вінниця : ВНТУ, 2013. 160 с.

6. Szkoda M., Kaczor G., Pilch R., Smolnik M., Konieczek Z. Assessment of the influence of preventive maintenance on the reliability and availability indexes of diesel locomotives. Transport Problems. 2021. Vol. 16. Issue 1. P. 5-18. DOI: 10.20858/tp.2017.12.2.10.

7. Barlow, R. E., and F. Proschan (1965). Mathematical Theory of Reliability. J. Wiley \& Sons. Reprinted (1996) SIAM, Philadelphia, PA. 274 p. 
8. Справочник по надежности : в 3 т. / под ред. Б. Е. Бердичевского. Москва : Мир, 1970. Т. 3. $376 \mathrm{c}$.

9. Ten W. M. \& Ghobbar A. A. Optimizing inspection intervals - Reliability and availability in terms of a cost model: A case study on railway carriers. Reliability Engineering and System Safety. 2013. Vol. 114. P. 137-147.

10. Рациональные режимы вождения поездов и испытания локомотивов / Е. В. Горчаков, И. П. Исаев, Л. Г. Козлов и др.; под общ. ред. С. И. Осипова. Москва : Транспорт, 1984. 280 с.

11. Скива Л., Яначек Я., Ценек П. Энергетически оптимальное управление транспортными системами / пер. с чеш. В. В. Космина. Москва, 1992. $247 \mathrm{c}$.

12. Блохин Е. П., Пшинько А. Н., Скалозуб В. В. Проблемы вождения поездов в условиях оптового рынка электроэнергии. Залізничний транспорт Украӥни. 2009. Вип. 6. С.10-15.

13. Тартаковський Е. Д., Устенко Крашенінін О. С., Обозний О. М. показників ТО при подовженні терміну експлуатації ТРС по наробці. 3б. наук. праць Укр. держ. акад. залізнич. трансп. Харків : УкрДУЗТ, 2012. Вип. 132. С. 5-11.

14. Крашенінін О. С., Харламов П. О Оцінка ефективності системи подовження терміну служби ТРС більш нормативного i оновлення експлуатаційного парку. Вісник Східноукраїнського університету ім. В. Даля: наук. журнал. Луганськ, 2012. Вип. 3(174). C. $109-113$.

\section{Крашенинин А. С., Шапатина О. А. Определение эффективности перевозок различными транспортными средствами.}

Аннотация. В данной статье рассмотрены вопросы определения эффективности перевозок различными транспортными средствами, которые рассматриваются как системы длительного действия. В соответствии с этим отмечена необходимость в рамках взаимодействия различных транспортных средств в процессе предоставления транспортных услуг комплексно учитывать способ выполнения задачи и этапы его выполнения.

Предложено в качестве критерия эффективности перевозок использовать критерий суммы значений множества вероятностей на показатель эффективности. Формализован процесс определения эффективности перевозок путем комбинирования способов перевозок на каждом этапе выполнения транспортных задач.

Ключевые слова: многофункциональная система, показатель технической эффективности, вероятность безотказной работы.
Krasheninin O., Shapatina O. Determination of transport efficiency by different vehicles.

Abstract. This article considers the issues of determining the efficiency of transportation by various vehicles, which are considered as long-term systems. Accordingly, the need for the interaction of different vehicles in the process of providing transport services to take into account the method of the task and the stages of its implementation.

Vehicles are used to perform tasks of moving goods or passengers between different destinations. Rail transport is used for mass transportation of goods and passengers over long distances. Road transport provides prompt delivery of goods and passengers in a much smaller lump sum. The advantages of intermodal transport are determined by its mobility, distance of transportation. The combination of the advantages of all modes of transport in a single process of traffic control allows to achieve high efficiency by choosing a route based on maneuvering the type of vehicle, its speed and load capacity. Since vehicles belong to the technical systems of long-term use, the task is to ensure high efficiency of their operation, ie to quantify the performance of vehicles of their functions. In the conditions of competition in the market of transport services the decision of this problem has actual character.

It is proposed to use the criterion of the sum of the values of the set of probabilities per efficiency indicator as a criterion of transportation efficiency. The process of determining the efficiency of transportation by combining the methods of transportation at each stage of transport tasks is formalized.

According to the above calculations, it is proved that the introduction of intermodal transport is the most efficient in comparison with other types of freight transport.

Keywords: multifunctional system, technical efficiency index, probability of trouble-free operation

Надійшла 23.04.2021 p

Крашенінін Олександр Семенович, доктор технічних наук, професор кафедри експлуатаиіі та ремонту рухомого складу, Украӥнський державний університет залізничного транспорту, Харків, Украӥна. E-mail: errs1@mail.ua. https://orcid.org/0000-0001-7462-3372.

Шапатіна Ольга Олександрівна, кандидат технічних наук, старший викладач кафедри управління вантажною $i$ комериійною роботою, Український державний університет залізничного транспорту, Харків, Україна. E-mail: uvkr@kart.edu.ua.https://orcid.org/0000-0002-91856212 .

Krasheninin Alexander Semenovich, Doctor of Technical Sciences, Professor, Department of Operation and Repair of Rolling Stock, Ukrainian State University of Railway Transport, Kharkiv, Ukraine. E-mail: errs1@mail.ua. https://orcid.org/0000-0001-7462-3372.

Shapatina Olha Oleksandrivna, PhD in Sci. Eng., Senior Lecturer of cargo and commercial work department, Ukrainian State University of Railway Transport, Kharkiv, Ukraine. E-mail: uvkr@kart.edu.ua. https://orcid.org/00000002-9185-6212. 